\title{
IMPLEMENTASI LAOD BALANCING PADA WEB SERVER MENGGUNAKAN APACHE DENGAN SERVER MIRROR DATA SECARA REAL TIME
}

\author{
Kresna Adi Pratama1, Ridho Taufiq Subagio², Muhammad Hatta ${ }^{3}$, Victor Asih \\ Universitas Catur Insan Cendekia \\ Jl. Kesambi 202, Kota Cirebon, Jawa Barat Tlp : (0231) 220250 \\ e-mail : kresna.adhie@gmail.com¹, ridho.taufiq@cic.ac.id², muhammad.hatta@cic.ac.id ${ }^{3}$, \\ victor.asih@cic.ac.id ${ }^{4}$
}

\begin{abstract}
ABSTRAK
PT.Trimitra Data Teknologi adalah perusahaan yang yang bergerak dalam bidang teknologi dan informasi, website menjadi salah satu cara jembatan komunikasi antara client dan perusahaan. Banyaknya client yang mengakses membuat beban sebuah web server dalam perusahaan menjadi berat dan menimbulkan masalah yaitu down nya server yang membuat client sulit untuk mengakses website perusahaan. Untuk membantu mengatasi masalah yang terjadi diterapkannya metode load balancing dengan algoritma request counting algorithm dimana bertujuan untuk membagi beban secara merata dalam web server dan memperkecil waktu respon antara client dan server, beban terbagi dengan anggota server yang terdaftar dalam server load balancing. Dengan penerapan metode load balancing maka kerja server akan menjadi lebih maksimal karena adanya sistem high availability dimana saat salah satu server mati maka kerja server akan diambil alih oleh server yang lain. Selain metode load balance penerapan sistem dengan server mirror yang dilakukan dapat membantu memaksimalkan metode load balance karena adanya replikasi otomatis antara web server yang menjadi anggota load balance baik konten website ataupun database. Hasil yang terjadi adalah web server perusahaan akan menjadi sistem yang mampu bekerja secara baik saat melayani client dalam hal layanan web server karena beban terbagi dengan baik dan kecilnya waktu respon sehingga tidak adanya kesulitan client untuk mengakses website perusahaan.
\end{abstract}

Kata kunci : Load Balance, Web Server, Mirror Server.

\begin{abstract}
PT.Trimitra Data Technology is a company engaged in the field of technology and information, the website becomes one of the bridges of communication between the client and the company. The number of clients that access makes the burden of a web server in the company becomes heavy and causes problems, namely the down server that makes it difficult for clients to access the company's website. To help overcome the problems that occur the implementation of the load balancing method with the request counting algorithm which aims to evenly distribute the load on the web server and reduce the response time between client and server, the load is shared with server members registered in the load balancing server. With the application of the load balancing method, server work will be maximized because of the high availability system where when one server dies the server work will be taken over by another server. In addition to the load balance method the application of the system with a mirror server can help maximize the load balance method due to automatic replication between web servers that are members of the load balance of website content or databases. The results that occur are the company's web server will be a system that is able to work well when serving clients in terms of web server services because the load is well divided and the response time is small so there is no difficulty for the client to access the company's website.
\end{abstract}

Keywords: Load Balance, Web Server, Mirror Server.

Implementasi Laod Balancing Pada Web Server Menggunakan Apache Dengan Server Mirror Data Secara Real Time (Kresna Adi Pratama, Ridho Taufiq Subagio, Muhammad Hatta, Victor Asih) 


\section{PENDAHULUAN}

\subsection{Latar Belakang Masalah}

Perubahan besar dalam dunia teknologi informasi sudah tidak bisa dipungkiri dimana bisa tercermin dalam meningkatnya juga pengguna internet yang menjadikannya sebagai media penyedia informasi. Dalam jaringan komputer server mempunya peranan penting dalam mengatur para client untuk mendapatkan informasi yang mereka butuhkan dan dengan semakin bertambahnya client yang mengakses maka beban server juga semakin bertambah dikarenakan banyak nya request dari client terhadap server. PT.Trimitra Data Teknologi adalah perusahaan yang bergerak dalam bidang IT dimana penggunaan web menjadi salah satu yang sangat dibutuhkan untuk membantu menyediakan layanan jasa dan tentunya web juga merupakan salah satu jembatan antara client dengan perusahaan karena tidak semua client mampu datang ke kantor secara langsung disaat tertentu, serta ada banyak juga client yang mengeluhkan tentang sulitnya mengakses website perusahaan. Ternyata terdapat kekurangan sistem dalam topologi yang berjalan pada perusahaan dimana masih belum menyediakan load balance karena hanya tersedia satu web server. Load balance merupakan salah satu penanggulangan jika suatu saat server menurun kinerjanya karena melayani banyak permintaan dari client secara bersamaan, perusahaan PT. Trimitra Data Teknologi menyayangkan kejadian tersebut bila terjadi, karena jika client yang sedang membutuhkan jasa dalam bidang IT terganggu saat mengakses website dalam hal ini tentu bisa sangat merugikan perusahaan. Maka sebab itu diterapkan solusi dengan metode load balance yang merupakan teknik untuk mendistribusikan beban trafik pada dua atau lebih jalur koneksi secara seimbang, agar trafik dapat berjalan optimal, memaksimalkan throughput, memperkecil waktu tanggap dan menghindari overload pada salah satu jalur koneksi. Dengan belum diterapkan nya teknik load balancing dalam web server PT. Trimitra Data Teknologi bisa menyebabkan beratnya kinerja server dalam sistem yang berjalan dan untuk mengatasinya maka penulis tertarik membuat judul "Implementasi Load Balancing pada Web Server Menggunakan APACHE dengan Server Mirror secara Real Time(Studi Kasus : PT. Trimitra Data Teknologi)".

\subsection{Identifkasi Masalah}

Berdasarkan latar belakang masalah yang didapat dari penjelasan diatas diuraikan beberapa identifikasi masalahnya :

1. Belum diterapkannya metode load balancing sehingga beban request masih tertumpu pada satu web server.

2. Sistem yang sedang berjalan kurang efisien dan rentan dalam ketersediaan layanan karena hanya tersedia satu web server.

3. Bagaimana membuat sebuah sistem yang memberikan ketersediaan layanan web server jika server down?

\subsection{Batasan Masalah}

Penulis membatasi permasalahan dalam penulisan ini agar pembahasan tidak menyimpang dari tujuan, maka dilakukan pembatasan masalah sebagai berikut :

1. Pembagian request dalam web server hanya menggunakan web server yang sudah diterapkan metode load balancing.

2. Layanan dalam web server menggunakan dua web server untuk memaksimalkan ketersediaan layanan.

3. Pembuatan sistem untuk ketersediaan layanan web server ketika down hanya menggunakan dua web server yang sudah di load balancing.

\subsection{Tujuan Penelitian}

Tujuan dari pembuatan load balance pada web server ini adalah :

1. Konfigurasi load balance yang dilakukan dapat membagi beban secara merata dan mampu meringankan kinerja server.

2. Membuat jaringan dimana server mampu menyediakan layanan yang baik untuk client dalam hal ini merupakan ketersediaan layanan yang terdapat dalam web server.

3. Load balancing pada web server juga dapat memberikan solusi failover yang terjadi dikarenakan akibat kegagalan sistem dari web server.

\section{KAJIAN PUSTAKA}

\subsection{Tinjauan Pustaka}

Pada penelitian yang berjudul "Analisis Load Balancing Pada Web Server Menggunakan Algoritme Weighted Least Connection" menyebutkan bahwa algoritma weighted least connection membagi jumlah 
koneksi yang dapat ditampung oleh suatu server dihitung dengan weight semakin besar weight maka server dapat menampung banyak koneksi dan pengujian sistem yang dilakukan pada penelitian diuji dalam beberapa pengujian dengan mengukur nilai throughput, response time dan CPU usage[1]. Lalu pada penelitian lainnya yang berjudul "Pengujian Algoritma Load Balancing pada Web Server Menggunakan NGINX" menjelaskan Dari hasil analisis pengujian menggunakan uji rata-rata kecepatan akses dari 2 populasi independen, yaitu dari algoritma round roubin dan least connection didapatkan hasil bahwa penggunaan algoritma least connection untuk load balancing lebih memberikan performa yang baik dibandingankan algoritma round robin terhadap kecepatan akses website saat terjadi request yang sangat banyak dari pengguna dalam waktu yang bersamaan[2]. Dan juga pada penelitian yang berjudul "Implementasi Load Balancing Web Server menggunakan Haproxy dan Sinkronisasi File pada Sistem Informasi“" Sistem load balancing dapat bekerja dengan baik ketika request datang dari client telah berhasil didistribusikan balancer secara merata kepada setiap node cluster. Sehingga server tidak mengalami overload dan kemampuan web server bisa melayani 10.000 request dengan tidak mengalami error request ,penerapan sinkronisasi file bekerja dengan baik dimana file yang diupload pada node 1 akan disinkron ke setiap node 2 dan node 3 pada cluster, begitu juga sebaliknya karena sinkronisasi file ini bersifat dua arah dan dengan implementasi clustering server dapat meningkatkan respon time web server dan meningkatkan jumlah current connection yang dapat dilayani oleh server [3].

\subsection{Dasar Teori}

\subsubsection{Jaringan Komputer}

Jaringan komputer didefinisikan sebagai sekumpulan komputer (lebih dari satu) yang terhubung satu dengan lainya menggunakan media tertentu sehingga memungkinkan diantara komputer tersebut berinteraksi, bertukar data, dan berbagi peralatan bersama misalkan printer, scanner dan sumber informasi lainnya[4].

\subsubsection{OSI Layer}

OSI layer adalah standar komunikasi yang dipakai atau diterapkan dalam suatu jaringan[5]. Terdapat 7 lapisan atau layer dalam OSI untuk memproses pertukaran data dalam sistem yang berlainan melalui hierarki atau tingkatan protokol komunikasi.

\subsubsection{TCP / IP}

TCP layer adalah standar komunikasi data yang sering di gunakan pada internet untuk suatu proses tukar - menukar atau saling mengirim data dari suatu komputer ke komputer lainnya dalam suatu jaringan internet[6]. TCP/IP memiliki 4 layer kumpulan protokol yang bertingkat.

\subsubsection{Sistem Operasi Linux}

Sistem operasi berbasis Linux dapat dirancang dan dilaksanakan melalui menggabungkan Linux (sebagai kernel dari sistem operasi) dan alat-alat lain seperti kompiler, konektor, perakit, dan alatalat tingkat yang lebih tinggi seperti editor teks dan intermediet grafis[7].

\subsubsection{Database}

Secara konsep basis data atau database adalah kumpulan dari data-data yang membentuk suatu berkas (file) yang saling berhubungan dengan tata cara yang tertentu untuk membentuk data baru atau informasi data (database) contoh dari database yang biasa digunakan yaitu MySQL yang merupakan sebuah perangkat lunak atau software sistem manajemen basis data $S Q L$ atau $D B M S$ Multithread dan multi user[8].

\subsubsection{Replikasi}

Replikasi adalah suatu teknik untuk melakukan copy dan pendistribusian data dan objek-objek database dari satu database ke database lain dan melaksanakan sinkronisasi antara database sehingga konsistensi data dapat terjamin[9].

\subsubsection{Web Server Apache}

Web server adalah sebuah perangkat lunak server yang berfungsi menerima permintaan HTTP atau HTTPS dari client yang di kenal dengan web browser, dan mengirimkan kembali hasilnya dalam bentuk halaman-halaman web yang umumnya berbentuk dokumen HTML beberapa jenis web server diantaranya Apache Web Server / The HTTP Web Server, Apache Tomcat, Internet Information Services[10]. 


\subsubsection{Load Balancing}

Load Balancing merupakan teknik untuk mendistribusikan beban trafik pada dua atau lebih jalur koneksi secara seimbang, agar trafik dapat berjalan optimal, memaksimalkan throughput, memperkecil waktu tanggap dan menghindari overload pada salah satu jalur koneksi[11].

\section{ANALISIS DAN PERANCANGAN SISTEM}

\subsection{Bahan dan Alat Penelitian}

\subsubsection{Bahan Penelitian}

Bahan penelitian merupakan bahan yang digunakan untuk melakukan penelitian, dalam perancangan dan pembuatan load balance pada web server akan membutuhkan data primer dan sekunder dari perusahaan terkait mengenai sistem sebelumnya. Pengumpulan data primer bisa dilakukan dengan wawancara terhadap seorang network administrator dimana dapat menghasilkan sebuah data berupa topologi yang sedang berjalan, alokasi IP Address dalam jaringan, jenis unit yang dipakai, spesifikasi unit meliputi hardware dan software dalam jaringan yang berjalan, jumlah unit yang sudah dipakai. Lalu untuk pengumpulan data sekunder dilakukan dengan cara membaca dan mempelajari literatur berupa buku, makalah, jurnal, artikel, atau bahan-bahan dari internet yang sesuai dengan topik yang sedang dibahas dalam penelitian ini, data yang telah didapat ini nantinya akan diolah dan dimasukan dalam sistem yang akan diusulkan sehingga mampu dianalisis dan diuji.

\subsubsection{Alat Penelitian}

Alat yang digunakan dalam penelitian memakai piranti tools-tools untuk membantu melakukan pengolahan atau pemberian perlakuan terhadap bahan penelitian.

1. Perangkat Keras (Hardware) yang akan dibutuhkan untuk pembuatan server :
a. PC dengan Processor I5 @ $2.4 \mathrm{GHz}$
b. RAM $8 \mathrm{~GB}$
c. Hardisk $500 \mathrm{~GB}$
d. Kabel UTP dengan konektor rj45

2. Perangkat Lunak (Software) yang dibutuhkan untuk mendukung pembuatan load balancing pada web server:
a. Sistem Operasi : window 10, CentOs 7
b. VirtualBox -6.0 .20$
c. Google Chrome - 83.0.4103.61
d. Microsoft Visio
e. APACHE Web Server
f. Lsyncd
g. MySQL

\subsection{Prosedur Penelitian}

Dalam tahapan ini prosedur ataupun metode yang digunakan adalah PPDIOO dimana model siklus hidup metode pengembangan jaringan dengan konsep PPDIOO ini, memberikan langkah-langkah kunci dalam keberhasilan perencanaan jaringan, baik itu pada tahapan desain, implementasi dan operasional nantinya. Pendekatan dengan model top-down design, mengarahkan infrastruktur jaringan untuk beradaptasi pada aplikasi-aplikasi apa saja yang dibutuhkan oleh suatu jaringan.

\subsection{Teknik Pengumpulan Data}

Pengumpulan data merupakan tahapan penting dalam proses penelitian, karena dengan mendapatkan data yang tepat maka riset akan berlangsung sesuai dengan perumusan masalah yang sudah ditentukan. Metode pengumpulan data yang penulis lakukan adalah dengan penelitian lapangan dan studi pustaka. Dalam tahapan ini. Penulis melakukan observasi maupun wawancara serta mempelajari teori-teori yang terkait dengan topik penelitian yang dapat mendukung pemecahan masalah penelitian. Pencarian referensi dilakukan di perpustakaan maupun secara online melalui internet. Selain itu, penulis juga mempelajari jurnal-jurnal dari hasi penelitian yang sudah pernah dikerjakan sebagai bahan perbandingan terhadap penelitian yang akan penulis kerjakan. Pustaka-pustaka yang dijadikan acuan dapat dilihat di Daftar Pustaka. 


\section{IMPLEMENTASI DAN PENGUJIUAN}

\subsection{Analisis}

Analisis merupakan sebuah langkah awal dalam pengembangan sebelum masuk dalam tahap lainnya, analisis dilakukan untuk mengetahui dasar dari suatu masalah yang terjadi dimana hasil dari analisis dapat dijadikan kajian untuk membuat sistem yang lebih efisien. Dalam hal ini penganalisisan dilakukan karena masalah yang timbul dari sistem yang telah berjalan dimana sistem tidak dapat memberikan dukungan terhadap sistem layanan ketika sedang mengalami masalah.

\subsubsection{Skema Jaringan}

Analisis ini dilakukan pada jaringan yang berjalan dan merupakan tahap awal, tahapan pertama akan dijabarkannya penjelasan tentang topologi yang sedang berjalan, internet, database dan layanan server.

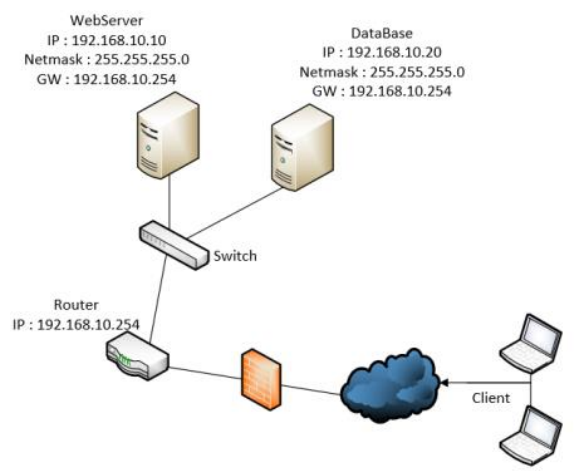

Gambar 1. Gambar Topologi Berjalan

Dari yang terlihat dalam gambar hanya ada satu web server dengan alamat IP 192.168.10.10/24 dengan gateway 192.168.10.254 dan juga database untuk penyimpanan data. IP Address berfungsi sebagai tanda pengenal dalam jaringan, disni terlihat layanan yang diberikan hanya mengandalkan dari satu web server dalam operasional normal tentu tidak akan menyebabkan banyak masalah untuk client tetapi jika saat server down maka akan menjadi suatu kelemahan dalam sistem nya. Client yang terhubung dengan internet bisa dapat mengakses langsung jaringan lokal web server.

\subsubsection{Pengalamatan IP Address}

Suatu jaringan tentunya tidak akan mungkin tanpa adanya IP Address karena merupakan sebuah identitas supaya bisa dikenal dalam jaringan baik lokal maupun tidak. Berikut adalah alamat IP Address yang digunakan.

\begin{tabular}{|c|c|c|c|}
\hline \multicolumn{5}{|c|}{ Tabel 1. Analisis IP Address } \\
\hline Perangkat & Alamat IP & Subnet Mask & Gateway \\
\hline Web Server & 192.168 .10 .10 & 255.255 .255 .0 & 192.168 .10 .254 \\
\hline Database Server & 192.168 .10 .20 & 255.255 .255 .0 & 192.168 .10 .254 \\
\hline Router & 192.168 .10 .254 & 255.255 .255 .0 & - \\
\hline
\end{tabular}

\subsubsection{Perangkat Keras Jaringan}

Perangkat keras berfungsi sebagai pengatur software, berikut adalah perangkat yang digunakan : Tabel 2. Analisis Perangkat Jaringan

\begin{tabular}{|c|c|c|c|}
\hline No & Nama perangkat & Spesifikasi & unit \\
\hline & & Intel Core i5 @ 2.40GHZ, RAM 8GB, Storage 500GB SSD, & 1 \\
1. & Web Server & Inter HD Grafis & 1 \\
\hline
\end{tabular}




\begin{tabular}{|c|c|c|c|}
\hline 2. & Database Server & $\begin{array}{c}\text { Intel Core i5 @ 2.40GHZ, RAM 8GB, Storage 500GB SSD, } \\
\text { Inter HD Grafis }\end{array}$ & 1 \\
\hline 3. & Router & $\begin{array}{c}\text { Mikrotik RB750,MIPS-BE,CPU ARZ7241 400MHz Main } \\
\text { Stroge 64MB, RAM 32 MB, LAN Ports 5, RouterOS, Level } \\
4\end{array}$ & 1 \\
\hline 4. & Modem & LAN Ports 5, Wi-Fi 2.4 / 5 GHz, Wired,WPS & 1 \\
\hline 5. & Switch & 5 port & 1 \\
\hline 6. & Kabel UTP 3M & Balden & 2 \\
\hline
\end{tabular}

\subsubsection{Perangkat Lunak Jaringan}

Supaya dapat mengatur input output yang masuk ke komputer dari perangkat keras, berikut adalah tabel perangkat lunak yang digunakan :

Tabel 3. Analisis Perangkat Lunak Jaringan

\begin{tabular}{|c|c|c|c|c|}
\hline No & Perangkat & Distro & Jenis OS & Service \\
\hline 1. & Web server & Linux & CentOS 7 & HTTP \\
\hline 2. & Database server & MySQL & MySQL & MariaDB \\
\hline 3. & Router & Mikrotik & RouterOS & MISP-BE \\
\hline
\end{tabular}

\subsection{Perancangan}

Perancangan merupakan sebuah langkah awal dalam pengembangan sebelum masuk dalam tahap lainnya, perancangan dilakukan untuk mengetahui kebutuhan apa saja yang akan di terapkan dan yang dibutuhkan. Dalam hal ini perancangan dilakukan untuk membuat sistem yang mampu memaksimalkan sistem yang berjalan.

\subsubsection{Topologi Usulan}

Setelah melihat adanya hal yang kurang dalam sistem yang sedang berjalan maka dari itu diajukannya sistem usulan untuk mengatasi masalah, berikut gambar topologi usulannya.

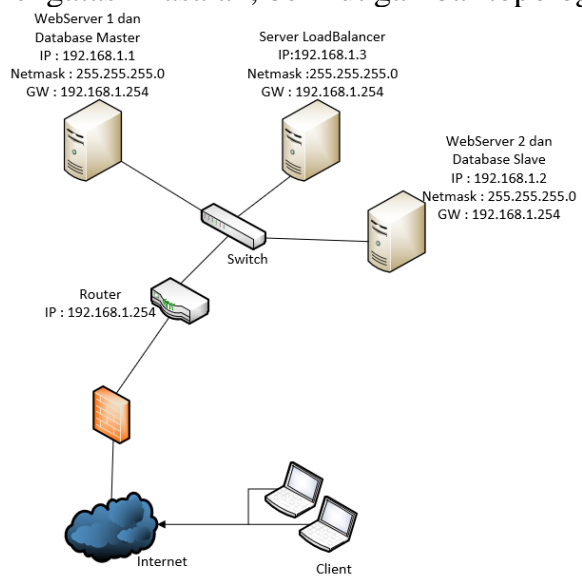

Gambar 2. Gambar Topologi Usulan

Dalam topologi yang diusulkan pada Gambar 2 terdapat beberapa tambahan berupa web server kedua dengan IP 192.168.1.2/24 dengan gateway 192.168.1.254 dan web server load balance dengan IP 192.168.1.3/24 dengan gateway 192.168.1.254 dimana semua terhubung dengan switch. Web server load balance merupakan tempat request client tertuju karena sebagai front end dari jaringan yang diusulkan. Database yang di usulkan pun bertambah yaitu database slave 192.168.1.2/24 karena letak database didalam web server kedua jadi IP yang digunakan mengikuti IP web server kedua, database diterapkan dengan sistem master dan slave untuk menjadi suatu solusi jika nanti database master mengalami kerusakan. Sedangkan kedua web server akan terkonfigurasi secara mirroring untuk memudahkan maintenance maupun pengubahan konten didalam layanan web server, hasil perubahan yang terjadi akan sama persis dengan apa yang dilakukan terhadap web server utama yaitu web server satu. Dengan adanya sistem seperti ini maka jaringan yang ada akan lebih maksimal dan para client yang mengakses akan 
mendapatkan layanan yang lebih baik karena sistem yang diusulkan sudah mendukung ketersediaan yang tinggi dalam hal pelayanan web.

\subsubsection{Perancangan Infrastuktur Usulan}

Perancangan terhadap infrastruktur menjadi suatu awal dalam langkah dimana dapat mengetahui dan menetapkan apa yang dibutuhkan dalam pembuatan jaringan.

Tabel 4. Perangkat Keras Usulan

\begin{tabular}{|c|c|c|c|}
\hline No & Nama perangkat & Spesifikasi & unit \\
\hline 1. & Web Server 1 & Intel Core i5 @ 2.40GHZ, RAM 8GB, Storage 500GB SSD, & 1 \\
Inter HD Grafis & Intel Core i5 @ 2.40GHZ, RAM 8GB, Storage 500GB SSD, & 1 \\
\hline 2. & Web Server 2 & Inter HD Grafis & 1 \\
\hline 3. & Server Load Balance & Intel Core i5 @ 2.40GHZ, RAM 8GB, Storage 500GB SSD, & 1 \\
\hline 4. & Router & $\begin{array}{c}\text { Mikrotik RB750,MIPS-BE,CPU ARZ7241 400MHz Main } \\
\text { Stroge 64MB, RAM 32 MB, LAN Ports 5, RouterOS, Level } \\
4\end{array}$ & 1 \\
\hline 5. & Modem & LAN Ports 5, Wi-Fi 2.4 / 5 GHz, Wired,WPS & 1 \\
\hline 6. & Switch & 5 port & 1 \\
\hline 7. & Kabel UTP 3M & Balden & 2 \\
\hline
\end{tabular}

\subsubsection{Alokasi IP Address}

Dibawah ini menunjukan alamat IP yang digunakan dalam perancangan infrastruktur usulan, IP merupakan tanda pengenal dalam jaringan yang digunakan.

Tabel 5. Alokasi IP Address

\begin{tabular}{|c|c|c|c|}
\hline Perangkat & Alamat IP & Subnet Mask & Gateway \\
\hline Web Server 1 dan DB Master & 192.168 .1 .1 & 255.255 .255 .0 & 192.168 .1 .254 \\
\hline Web Server 2 dan DB Slave & 192.168 .1 .2 & 255.255 .255 .0 & 192.168 .1 .254 \\
\hline Server Load Balance & 192.168 .1 .3 & 255.255 .255 .0 & 192.168 .1 .254 \\
\hline Router & 192.168 .1 .254 & 255.255 .255 .0 & - \\
\hline
\end{tabular}

\subsubsection{Perangkat Lunak}

Komponen pendukung yang dimaksudkan adalah merupakan sebuah komponen yang bersifat perangkat lunak yang diperlukan dalam membantu pembuatan jaringan yang akan diusulkan.

Tabel 6. Komponen Pendukung

\begin{tabular}{|c|c|c|c|}
\hline No & Nama Paket & Sumber & Fungsi \\
\hline 1. & Linux CentOs 7 & https://centos.org & Sistem Operasi dalam server \\
\hline 2. & Apache & Repositories CentOs 7 & Aplikasi pembuatan web server \\
\hline 3. & Lsyncd & Repositories CentOs 7 & Aplikasi mirror dalam web server \\
\hline 4. & MySQL & https://dev.mysql.com & Database untuk server \\
\hline
\end{tabular}

Implementasi Laod Balancing Pada Web Server Menggunakan Apache Dengan Server Mirror Data Secara Real Time (Kresna Adi Pratama, Ridho Taufiq Subagio, Muhammad Hatta, Victor Asih) 


\subsubsection{Arsitektur Load Balancing}

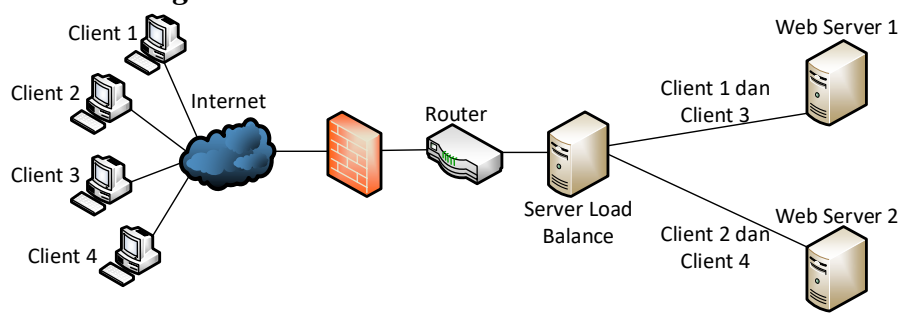

Gambar 3. Pembagian Kuota Load Balance

Dalam pembagian request client yang menuju ke server load balance maka akan terbagi secara merata karena ada nya konfigurasi sticky session karena jika tanpa sticky session maka tidak ada nya pembagian merata karena client akan dilayani oleh 2 web server secara bergantian ketika akan melakukan request ulang, sticky session merupakan cara supaya user diberi penanda biasanya berupa cookie. Setelah client diberikan tanda maka server load balance akan membaca cookie tersebut dan mengarahkan ke server yang sudah pernah mengurus client tersebut. Dalam gambar bisa terlihat bahwa client 1 dan client 3 akan dilayani oleh web server 1 sedangkan untuk client 2 dan client 4 akan dilayani oleh web server 2 . Sticky session dalam konfigurasi di server load balance yang dilakukan menggunakan header cookie dimana client diberi penanda sebelum masuk lalu untuk web server akan terbagi menjadi 2 yaitu web server 1 berada dalam route ke 1 dan web server 2 akan berada dalam route 2 setelah dilakukan konfigurasi tersebut maka server load balancer dapat membaca perubahan route untuk layanan pada web server yang menjadi member dalam server load balance.

\subsubsection{Mirror Data}

Penerapan server dalam usulan juga menggunakan konfigurasi mirror yaitu untuk memudahkan server mempunyai replikasi dari konten web server maupun isi database tanpa harus mengkonfigurasi web server dan database server yang kedua, mirror ini dapat menghemat waktu dalam perubahan yang terjadi dalam konten web server maupun isi dalam database karena saat selesainya pekerjaan dalam web server pertama atau melakukan perubahan dalam database pertama maka akan terreplikasi secara identik terhadap web server kedua dan database kedua. Setelah server master membuat database hal pertama yang dilakukan adalah menyamakan nilai variabel dari log database yang terbuat di server master untuk menandakan database mana yang akan di mirror, setelah itu selanjutnya setiap perubahan dalam database server master yang tercatat di binary log server master akan dibaca oleh $I / O$ thread server slave yang kemudian akan dicatat dalam relay log server slave. Karena perubahan data sudah berada dalam relay log server slave maka selanjutnya $S Q L$ thread akan bekerja untuk membaca data dalam relay log yang kemudian akan dimasukan menjadi data dalam database server slave.

\subsection{Implementasi Dan Pengujian}

\subsubsection{Implementasi}

Merupakan sebuah tindakan yang dilakukan setelah melakukan analisis dan perancangan, dalam

hal ini implementasi dilakukan dalam langkah-langkah berupa installasi dan konfigurasi.

\subsubsection{Installasi $O S$}

Sistem operasi merupakan sebuah sistem perangkat lunak yang berfungsi sebagai pengatur sumber daya dari hardware dan software, berikut langkah-langkah untuk melakukan install OS.

\subsubsection{Konfigurasi IP statik}

Konfigurasi IP static dilakukan supaya tidak berubah saat server reboot dan untuk menetapkan alamat address server itu sendiri serta memudahkan konfigurasi antar server sedangkan jika memakai IP DHCP maka IP server akan bisa terus berubah jika dilakukan reboot, hal pertama yaitu masuk dalam script enp0s3.

\subsubsection{Install Apache}

HTTP merupakan protokol yang digunakan halaman browser untuk menampilkan halaman website dari web server. Web server merupakan server yang mengirimkan HTTP response ke browser dan memprosesnya menjadi halaman web.

\subsubsection{Konfigurasi Apache}

Setelah install selesai maka jalankan service dari HTTP dengan cara systemctl start httpd.service dan systemctl enable httpd.service, dua fungsi command tersebut adalah pertama menjalankan service dan kedua jika server dilakukan reboot maka service akan berjalan secara otomatis. 


\subsubsection{Install Lsyncd \\ Lsyncd merupakan tool yang digunakan untuk melakukan replikasi terhadap data-data yang berada dalam direktori tertentu dalam server, dalam hal ini target untuk replikasi adalah direktori /var/www/html. Dalam proses replikasi antar server harus bisa dilakukan tanpa perlu menginput password lagi maka dari itu pertama dilakukan pembuatan keygen untuk memudahkan komunikasi antara server.}

4.3.1.6 Konfigurasi Lsyncd

Pertama jalankan daemon dengan command lsyncd -rsync /var/www/html/ /192.168.1.2:/var/www/html/, untuk /var/www/html/ itu adalah source dari direktori yang ingin dilakukan mirror sedangkan /192.168.1.2:/var/www/html/ adalah target dan direktori mana akan diletakannya hasil mirror.

\subsubsection{Install MySQL}

MySQL merupakan sebuah software management database yang digunakan untuk menyimpan data-data dengan terstruktur, berikut langkah yang dilakukan untuk menginstall $M y S Q L$ dengan menerapkan sistem master slave yang bertujuan untuk melakukan otomatisasi replikasi database tertentu sehingga dapat memaksimalkan high availability dalam database.

\subsubsection{Konfigurasi MySQL}

Setelah install paket mariaDB lalu untuk menjalankan nya masukan command systemctl start mariadb dan systemctl enable mariadb. Untuk mengamankan database setelah melakukan installasi maka harus terlebih dahulu melakukan konfigurasi untuk mengganti password dengan command mysql secure installation.

\subsubsection{Konfigurasi Load Balancing}

Load balance dilakukan untuk membagi beban secara merata di antara web server yang terdaftar sebagai anggota load balance, konfigurasi ini dilakukan oleh server load balance dimana bertindak sebagai front end dan web server menjadi back end.

\subsubsection{Pengujian}

\subsubsection{Database Master dan Slave}

Hasil dari konfigurasi yang pertama adalah dengan menampilkan sistem master server yang berjalan, database yang akan di mirror dinamakan dengan trimitra dengan tabel user didalamnya sebagai hasil dari sistem master slave database.

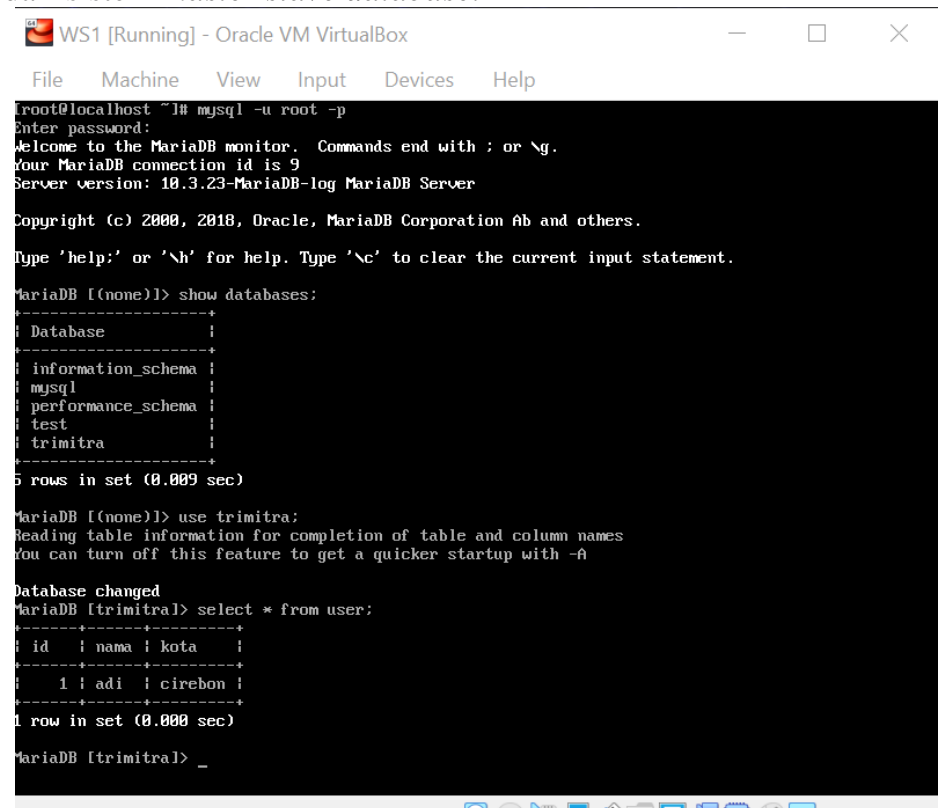

Gambar 4. Database Web Server 1

Implementasi Laod Balancing Pada Web Server Menggunakan Apache Dengan Server Mirror Data Secara Real Time (Kresna Adi Pratama, Ridho Taufiq Subagio, Muhammad Hatta, Victor Asih) 
Dalam database web server kedua terdapat juga database trimitra dengan tabel user sebagai contoh dari hasil konfigurasi sistem master slave database. Isi dari tabel user akan otomatis berubah mengikuti perubahan yang terjadi dalam database server master.

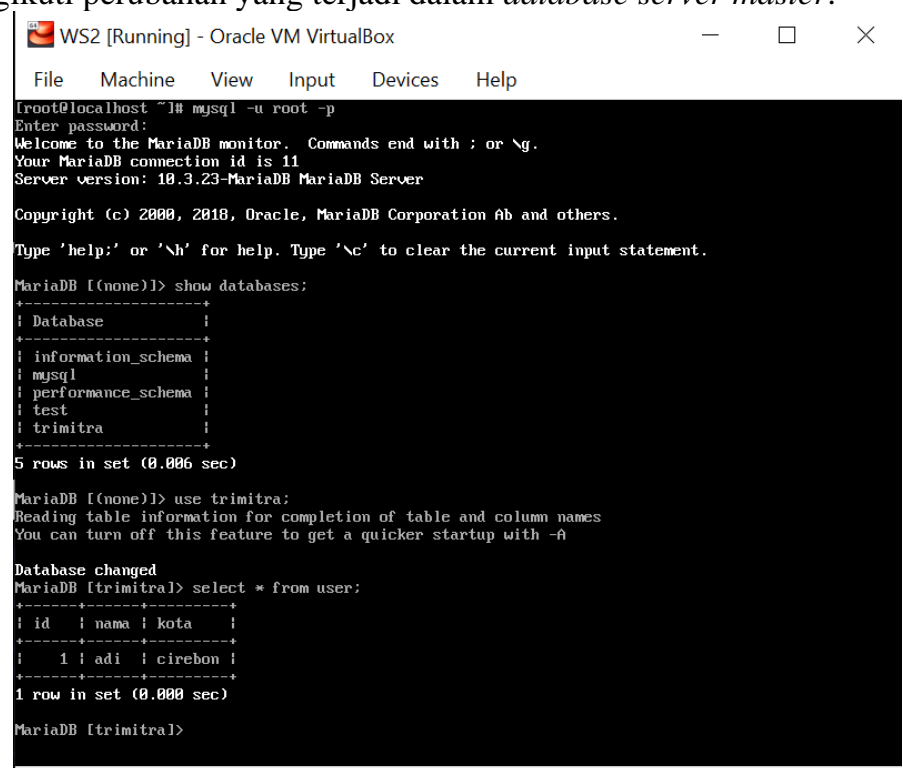

\section{Gambar 5. Database Web Server 2}

\subsubsection{Mirror Server}

Lalu untuk hasil mirror konten web server dalam /var/www/html dilakukan dengan pembuatan direktori dari sisi web server satu dengan nama data replika.

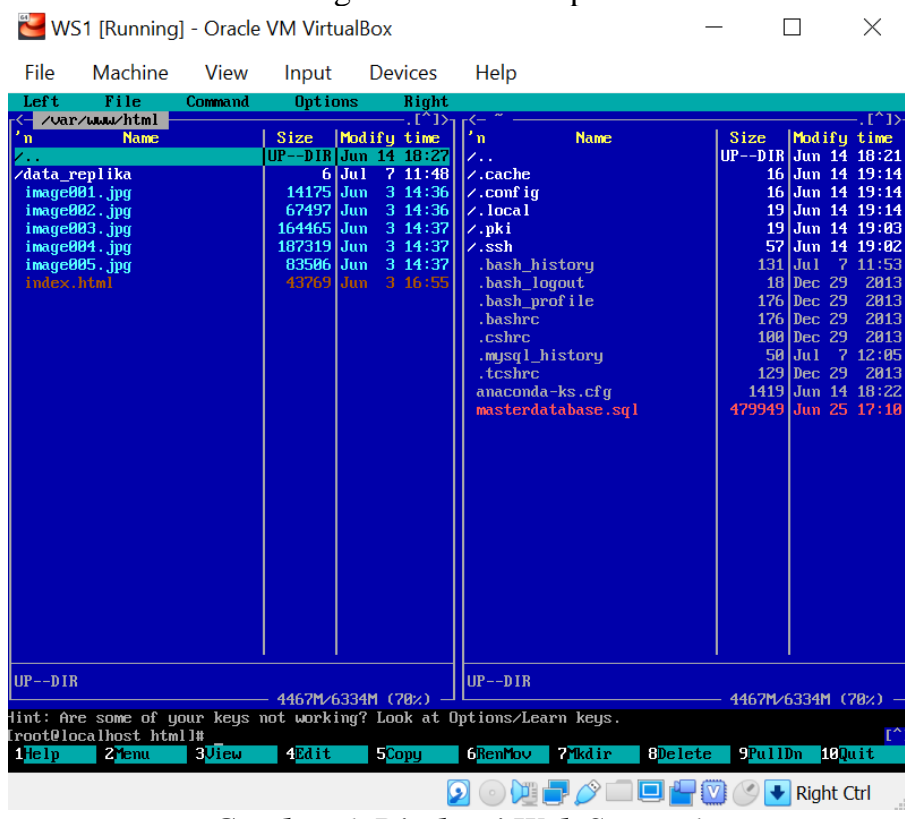

Gambar 6. Direktori Web Server 1

Direktori yang telah dibuat dalam $/$ var/www/html web server satu akan terbuat juga dalam web server dua dikarenakan adanya proses sinkronisasi yang terjadi dengan interval waktu tertentu dan real time. Perubahan dari pembuatan baru maupun penghapusan direktori hingga perubahan isi file dari web server satu akan selalu di cek oleh web server dua. 


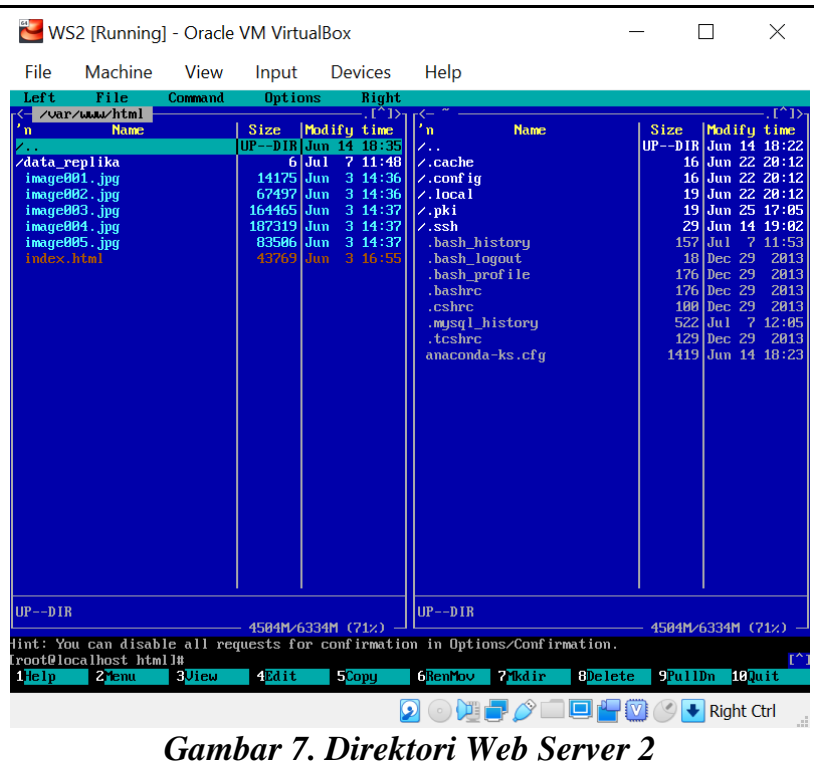

\subsubsection{Load Balance}

Gambar 7. Direktori Web Server 2

Pengujian berikut sudah diterapkannya sistem load balance. Load balance dapat berjalan dengan baik dan terjadinya pembagian beban secara merata oleh anggota nya dalam hal ini merupakan web server yang menyediakan layanan web. Dapat terlihat pengaksesan layanan web melalui dua browser, client pertama mendapat tampilan layanan web dari web server satu.

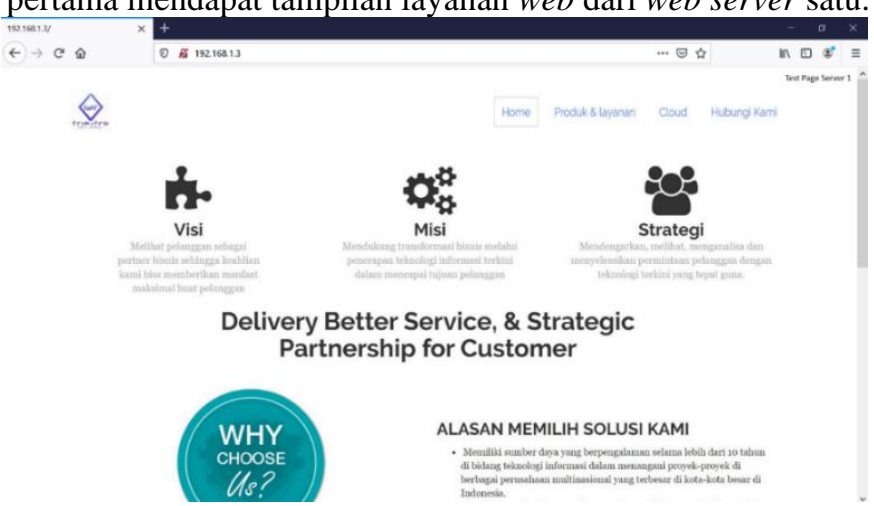

Gambar 8. Layanan Web Server 1

Lalu browser kedua akan mendapat tampilan web dari web server dua karena sistem nya adalah membagi beban secara merata dan berurutan, maka saat client baru akan mengakses lagi selanjutnya akan dilayani oleh web server satu.

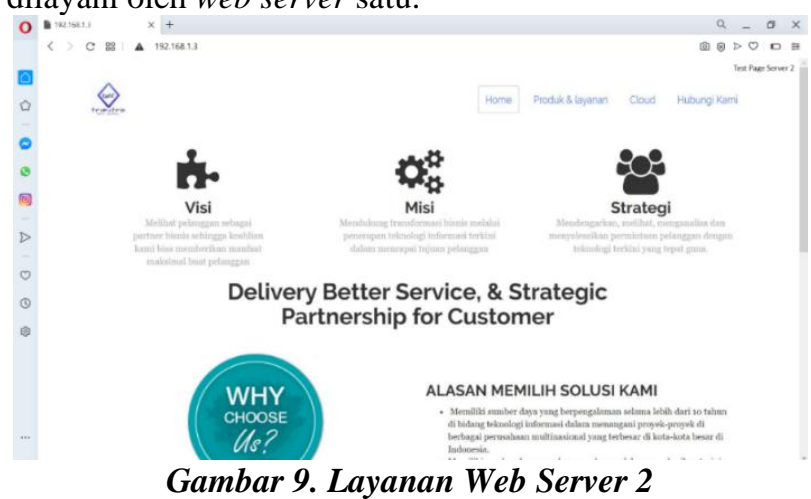

Implementasi Laod Balancing Pada Web Server Menggunakan Apache Dengan Server Mirror Data Secara Real Time (Kresna Adi Pratama, Ridho Taufiq Subagio, Muhammad Hatta, Victor Asih) 


\section{KESIMPULAN DAN SARAN}

\subsection{Kesimpulan}

Dari penelitian yang dilakukan dapat diuraikan beberapa kesimpulan :

1. Beban server dapat terbagi karena masing-masing web server mampu mengidentifikasi client yang membutuhkan layanan dengan memberi tanda dalam header session sehingga tiap client baru yang akan mengakses akan dilayanin sesuai dengan route web server.

2. Load balance dapat membantu memaksimalkan ketersediaan dalam layanan web server karena load balance mempunyai beberapa anggota web server.

3. Terbentuknya sistem failover karena konfigurasi sistem load balance yang dapat mengalihkan layanan web server jika salah satu dari anggota load balance mengalami masalah.

\subsection{Saran}

Adapun saran yang perlu menjadi pertimbangan untuk perkembangan penelitian selanjutnya yaitu Pengembangan kedepannya bisa dapat membandingkan performa jenis load balance yang ada pada penelitian ini dengan jenis load balance yang lain agar dapat mengetahui konfigurasi performa server yang lebih baik.

\section{DAFTAR PUSTAKA}

[1] D. Rahmana, R. Primananda, and W. Yahya, "Analisis Load Balancing Pada Web Server Menggunakan Algoritme Weighted Least Connection," J. Pengemb. Teknol. Inf. dan Ilmu Komput. Univ. Brawijaya, vol. 2, no. 3, pp. 915-920, 2017, doi: 10.1016/0028-3932(72)90008-5.

[2] D. K. Hakim, D. Y. Yulianto, and A. Fauzan, "Pengujian Algoritma Load Balancing pada Web Server Menggunakan NGINX," JRST (Jurnal Ris. Sains dan Teknol., vol. 3, no. 2, p. 85, 2019, doi: 10.30595/jrst.v3i2.5165.

[3] A. Rahmatulloh and F. MSN, "Implementasi Load Balancing Web Server menggunakan Haproxy dan Sinkronisasi File pada Sistem Informasi Akademik Universitas Siliwangi,” J. Nas. Teknol. dan Sist. Inf., vol. 3, no. 2, pp. 241-248, 2017, doi: 10.25077/teknosi.v3i2.2017.241-248.

[4] H. Yuliandoko, Ed., "Jaringan Komputer Wire dan Wireless," in Jaringan Komputer, 1st ed., DEEPUBLISH (Grup Penerbitan CV BUDI UTAMA), 2018, p. 4.

[5] S. S. Mulyanta, "Pengenalan Protokol Jaringan Wireless Komputer," Google Book. CV ANDI OFFSET, p. 172, 2017.

[6] E. Haryanto, “Jaringan Komputer TCP IP.pdf.” CV ANDI OFFSET, p. 167, 2012.

[7] E. B. Harjono, "Analisa Dan Implementasi Dalam Membangun Sistem Operasi Linux Menggunakan Metode LSF Dan REMASTER," Informatika, vol. I, no. 1, pp. 30-35, 2016.

[8] Y. Swara, G. Y. Kom. M., \& Pebriadi, "Rekayasa Perangkat Lunak Pemesanan Tiket Bioskop Berbasis Web," J. TEKNOIF, vol. 4, no. 2, pp. 27-39, 2016.

[9] H. Maulana, "Analisis Dan Perancangan Sistem Replikasi Database Mysql Dengan Menggunakan Vmware Pada Sistem Operasi Open Source," InfoTekJar (Jurnal Nas. Inform. dan Teknol. Jaringan), vol. 1, no. 1, pp. 32-37, 2016, doi: 10.30743/infotekjar.v1i1.37.

[10] Sumarna, "Perancangan Clustering Ujian Online Studi Kasus Bina Sarana Informatika," J. Techno Nusa Mandiri, vol. XII, no. 1, pp. 35-40, 2015.

[11] S. Riskiono, "Implementasi Metode Load Balancing Dalam Mendukung Sistem Kluster Server," Semnas Ristek, pp. 455-460, 2018. 